\title{
Investigation of expanding Split Sets
}

\author{
G.R. Davison Mining One Pty Ltd, Australia
}

P.G. Fuller Mining One Pty Ltd, Australia

\begin{abstract}
Expanding rockbolts anchor to the rock mass using friction and mechanical interlocking at the rockbolt interface. An internally expanding friction rockbolt is capable of generating much higher radial force along its entire length than standard friction bolts. This results in increased friction between the rock mass and the friction bolt. Tubular form expanding friction bolts have never gained a following in Australia due to perceived installation issues, relatively low tensile strength and corrosion problems associated with the thin expansion walls. This paper shows that Jumbo installation of expanding friction rockbolts is now possible with the same ease as traditional 'Split Set' style friction bolts. The expanding friction bolt discussed in this paper has the same material properties as conventional friction bolts, but provides increased corrosion protection and increased anchorage capacity per embedded metre due to the expanding properties of its grout core.
\end{abstract}

\section{$1 \quad$ Introduction}

From their first introduction, the fundamental requirements for rockbolts have changed little. Generally these are:

- Rockbolts must be long enough to penetrate de-stressed and/or loosened ground and anchor into more competent ground.

- Rockbolts must have sufficient strength to secure the loosened ground in position.

- Rockbolts must develop sufficient anchor strength to enable a high proportion of their tensile strength to be utilised.

A more recent additional requirement is the ability of rockbolts to absorb energy in specific situations.

In 1973, Dr James Scott conceived and patented the friction rock stabiliser and it was eventually marketed as the Split Set ${ }^{\mathrm{TM}}$. Initially the $33 \mathrm{~mm}$ and $39 \mathrm{~mm}$ diameter version of this bolt was installed with airlegs in boreholes of smaller diameter to achieve an interference fit. By the early 1980s, practitioners in Australia began to install larger $46-47 \mathrm{~mm}$ diameter Split Sets with jumbos in a hole that was normally used for explosive containment when advancing a development face, i.e. a $45 \mathrm{~mm}$ diameter hole. The nominal 46-47 mm diameter version is still widely used in Australian metalliferous mines.

A deficiency with the Split Set is the relatively low friction between the device and the rock mass. Typically for a $47 \mathrm{~mm}$ bolt, on site testing shows frictional anchorage of between $4-6 \mathrm{t} / \mathrm{m}$ of bolt embedment. This has been taken as the standard base level requirement for many mines, i.e. to be recorded as a successful test, a $2.4 \mathrm{~m}$ long bolt is to be pull tested to $10 \mathrm{t}$ without slip.

Efforts have been made to increase this friction by grouting the inside of the bolt.

Fuller and Dugan (1992) first quantified this feature when testing rockbolts at Broken Hill, Australia. In their testing program they recorded increased frictional anchorage with grouted Split Sets and a similar further increase when Split Sets were grouted with an internal $15.2 \mathrm{~mm}$ diameter cable.

Villaescusa and Wright (1997) describe a similar testing program and recorded increased friction of up to $18 \mathrm{t} / \mathrm{m}$ in relatively good ground. They claimed that this increase was: 
"... mainly due to the " partial dowelling and interlocking effect" achieved by the high strength grout being in contact (bonded) with the rock all the way along the split axis of the bolt."

They also stated:

"The frictional resistance along the entire bolt axis is also increased by the high compressive strength grout minimising any inward deformation in the bolt needed to achieve bolt slippage".

Thompson and Finn (1999) concurred with this view stating:

"The writers agree with both these proposed mechanisms of increased load transfer." and

"...the first mechanism is most likely to be the cause of the increased load transfer." (Referring to the grout making contact with the rock).

Importantly, Thompson and Finn (1999) presented graphs showing the variation in diameter along the length of percussively drilled boreholes. The variations were up to a few millimetres and for this reason the gap across the slit in installed Split Sets can be seen to vary along its length coinciding with the different borehole diameters. Davison (2008) demonstrated that the second mechanism, i.e. the prevention of inward deformation is the primary reason for the increased bond strength.

The Stiff Split Set ${ }^{\mathrm{TM}}$ utilises internal grouting to increase the friction of the installed product. The Stiff Split Set is a modified Split Set that allows grouting to occur as the bolt is installed thereby eliminating the necessity of a secondary grouting operation. It includes a flap which is a thin steel strip fixed to the inner surface of the bolt to retain the hydrated cement grout cartridge during installation. A one pass process cannot occur with a normal Split Set. To maintain a low unit cost the flap is made of thinner material than that of the Split Set. It is fixed on one edge of the bolt allowing the other edge of the flap to move during installation. To date approximately 750,000 of the Stiff Split Set bolts have been installed in Australia and elsewhere. The friction developed by this product depends on the ground in which it is installed; however, typical frictional values in excess of $10 \mathrm{t} / \mathrm{m}$ have been achieved in Fair to Good ground. The benefit of this increased frictional anchorage is that more of the tensile strength of the bolt can be utilised. In the ungrouted version, in the best situations, the mine operator can only expect a $2.4 \mathrm{~m}$ long Split Set to develop 10-13.5 t, i.e. 4 to $6 \mathrm{t} / \mathrm{m}$, in a pull-out test even though an $18 \mathrm{t}$ tensile capacity bolt has been purchased. With the grouted Stiff Split Set version in the same situation the full $18 \mathrm{t}$ capacity of the bolt can be utilised.

Various mine sites have different requirements with respect to ground support. Put simply, there are some sites that require stiff support while others require ductile support. In many cases, mine sites require simple, cost effective stiff support in poor to extremely poor ground conditions. Grouting of Split Sets is one way to achieve this, but in extremely poor ground even this grouting does not generate the desired bond strength and stiffness.

Discussions on this topic prompted the authors to investigate methods of increasing the bond strength of grouted Spilt Sets in these poor ground conditions.

A prototype of a one pass installation 'swelling' Stiff Split Set for poor ground conditions has been developed and even though product development is at an early stage, significant improvements in bolt friction in very poor ground have already been achieved. In the expanding device the thinness of the flap material, means that the flap can conform readily to the profile of the hole as the cement grout expands.

\section{$2 \quad$ Methodology}

A Split Set deforms upon installation according to the borehole dimensions in which it is installed.

In hard rock conditions the variation in the installed Split Set diameter is due to minor variations in borehole diameter created when percussive drilling occurs. By grouting the Split Set the radial stiffness of the bolt is increased thus increasing the friction between the bolt and the hole in the borehole. In soft ground conditions the radially stiff grouted Split Set bolt deforms the borehole as it slips and as a result, there is an upper limit to the frictional gain that can be developed by grouting alone. 
Relatively poor anchorage with tubular friction bolts has been recognised as a problem for some time. Success in solving this has been achieved with the Swellex ${ }^{\mathrm{TM}}$ bolt which is inflated by high pressure water and deformed to the shape of the borehole. In very soft ground the expanded bolt is highly likely to deform the ground surrounding the bolt. A problem with the most common and cost effective version of this bolt is the relatively low tensile strength, i.e. 10-12t compared to the relatively high friction that it can develop. This has resulted in its tensile failure in an overload situation.

The use of specialised swelling grouts is relatively common in the construction industry. A series of tests was undertaken to determine the applicability of the expansive capabilities of these grouts. The chemical composition of such products is proprietary knowledge and it is common to achieve an expansive pressure of approximately $125 \mathrm{MPa}$ with these products.

Figures 1 and 2 show the ultimate swelling of a capsule over a one month period. Notice the reference coin is approximately the same size in each figure.

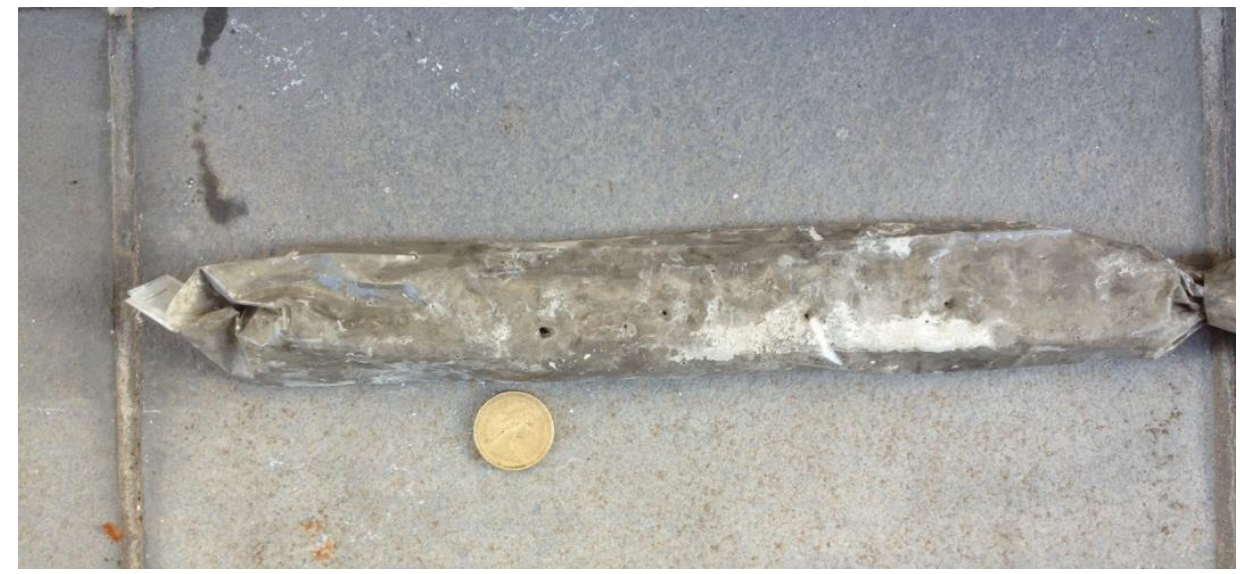

Figure 1 Swelling grout in sausage form immediately after hydration

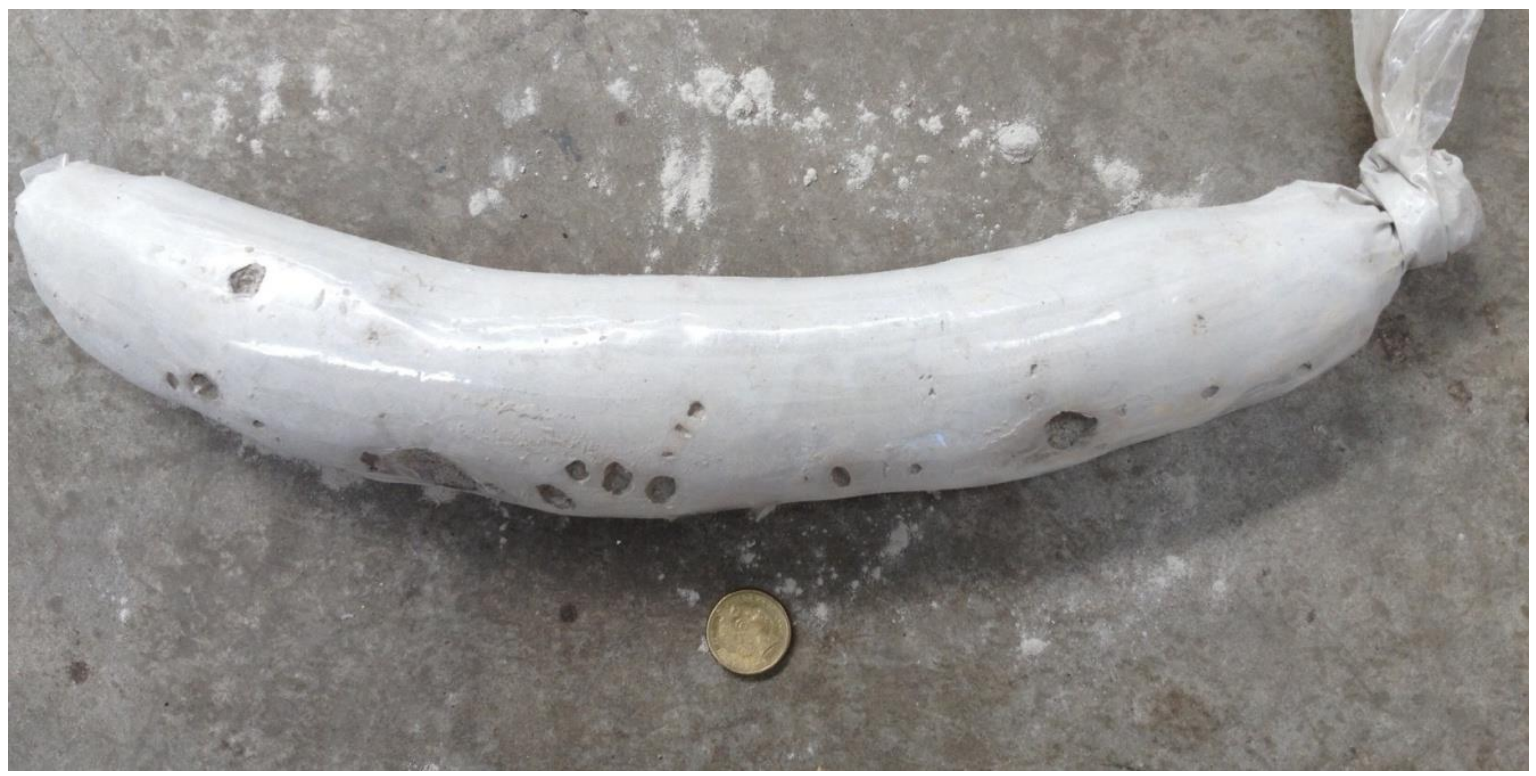

Figure 2 Capsule of swelling grout after one month

The first series of tests was conducted on a non-restrained, i.e. out of a bore hole Stiff Split Set.

A hydrated cartridge similar to that shown in Figure 1 was placed in a Stiff Split Set and the diameter was measured as expansion of the swelling grout progressed. Figure 3 is a photo of the swelling of part of the Stiff Split Set bolt which had an initial diameter of $46.0 \mathrm{~mm}$. 


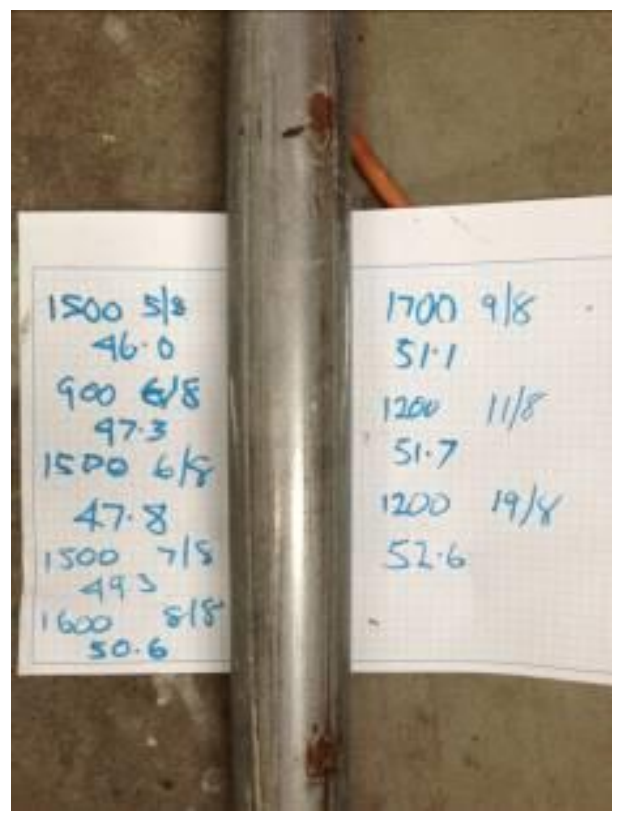

\section{Figure 3 Swelling of a Stiff Split Set}

Diameter measurements of the expanding Stiff Split Set in an unrestrained condition are presented in Table 1 and shown graphically in Figure 4.

Table 1 Diameter of Stiff Split Set at various times after insertion of a hydrated expanding grout cartridge

\begin{tabular}{ccc}
\hline Date & Time & External Diam. $(\mathbf{m m})$ \\
\hline $05 / 08 / 2012$ & 1500 & 46.0 \\
$06 / 08 / 2012$ & 0900 & 47.3 \\
$07 / 08 / 2012$ & 1500 & 49.3 \\
$08 / 08 / 2012$ & 1600 & 50.6 \\
$09 / 08 / 2012$ & 1700 & 51.1 \\
$11 / 08 / 2012$ & 1200 & 51.7 \\
$19 / 08 / 2012$ & 1200 & 52.6 \\
$24 / 08 / 2012$ & 0900 & 53.0 \\
$26 / 08 / 2012$ & 1200 & 53.2 \\
$25 / 09 / 2012$ & 1200 & 54.2 \\
$30 / 09 / 2012$ & 1200 & 54.8 \\
\hline
\end{tabular}

The data shows an increase in diameter of the Stiff Split Set from 46 to $51.1 \mathrm{~mm}$ in 4 days. Expansion continues after this with the rate of expansion decreasing after approximately 6 days. Measurements ceased after 56 days with a total expansion from 46 to $54.8 \mathrm{~mm}$, i.e. $19 \%$. 


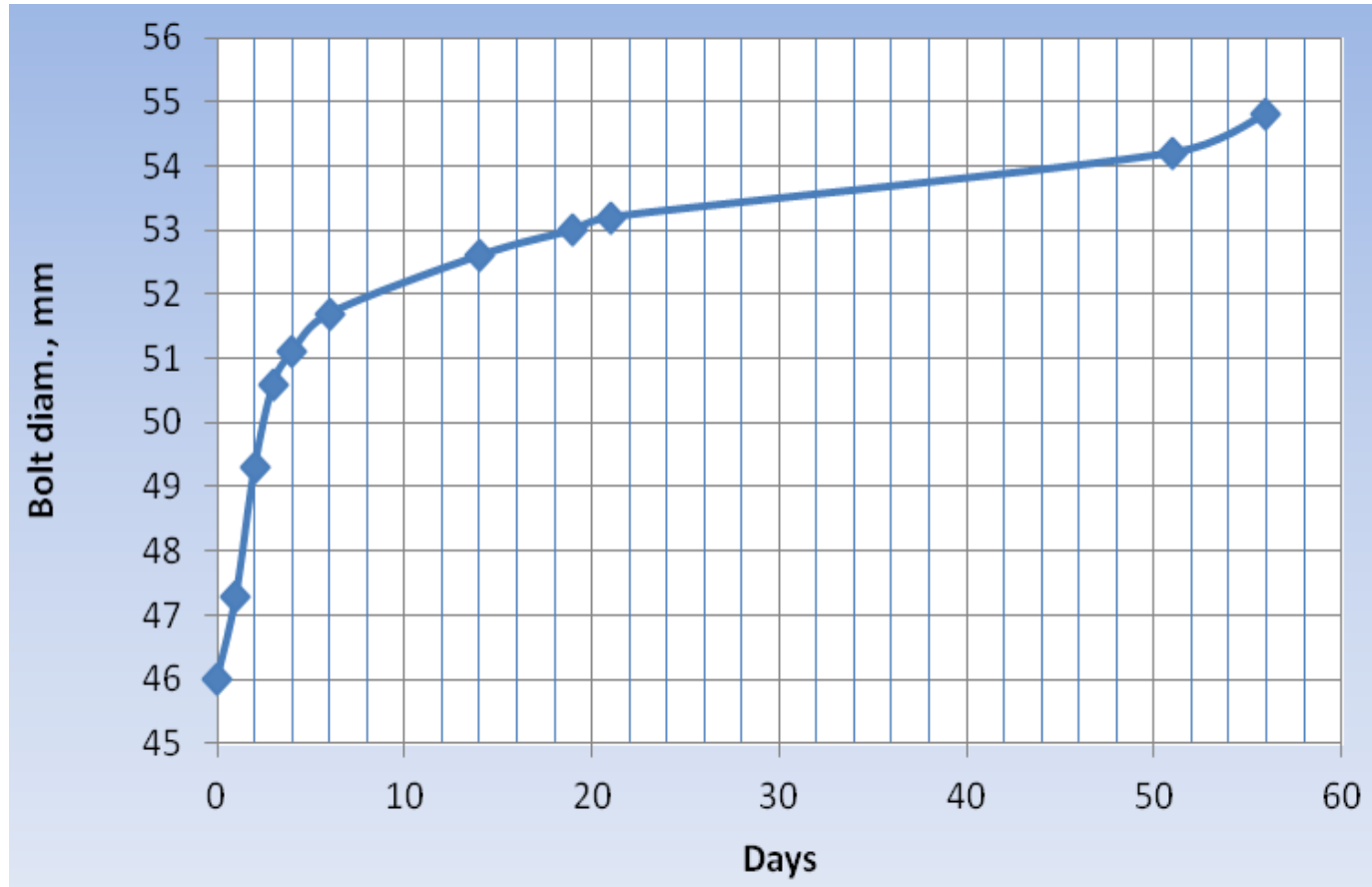

\section{Figure 4 Bolt diameter increase after insertion of expanding grout cartridge}

The unrestrained test of the Stiff Split Set eventually ruptured the retaining flap which can be seen in Figures 5 and 6 . Note that the rupturing occurred some time after diameter measuring ceased.

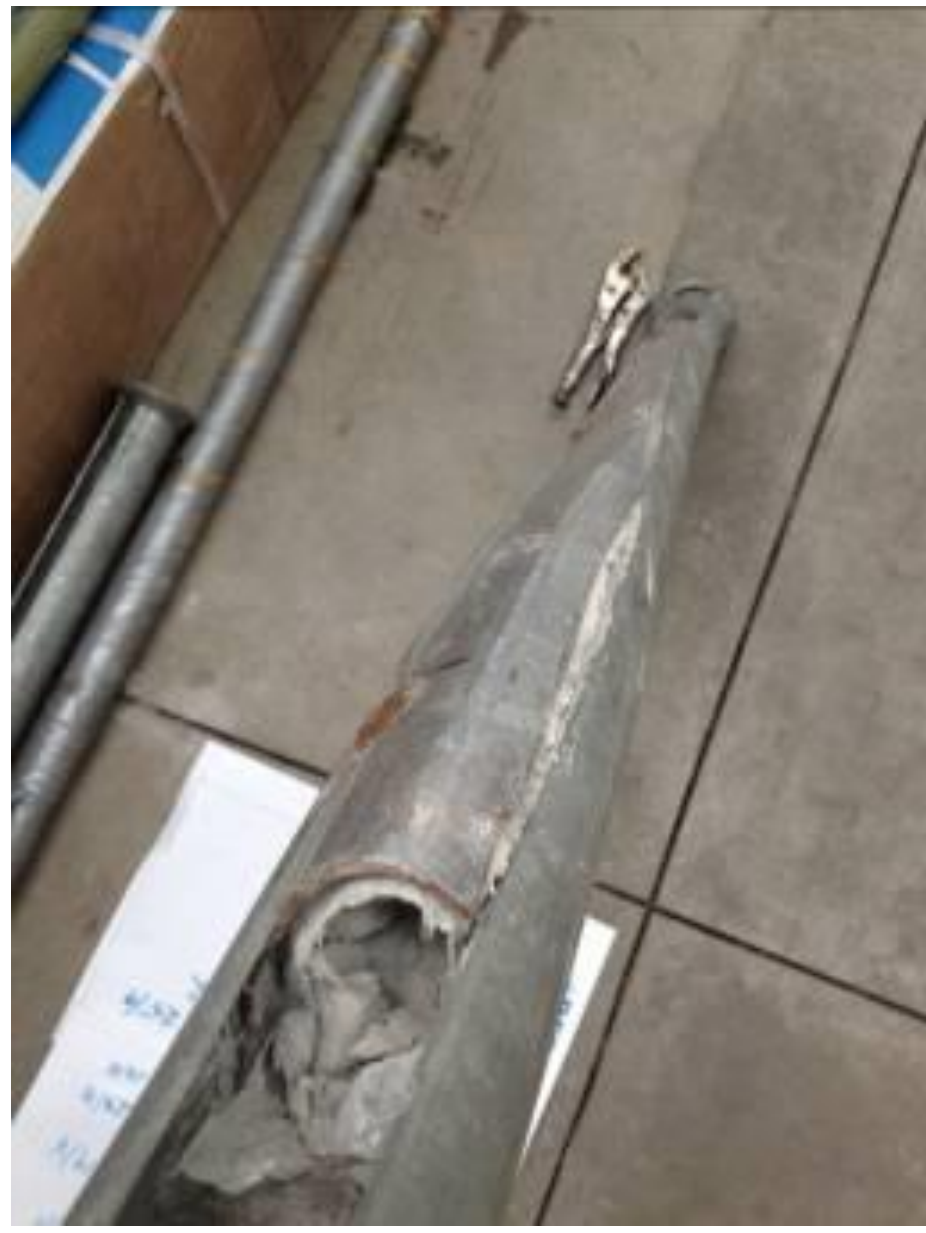

Figure 5 Beginning of Stiff Set bolt flap rupture 


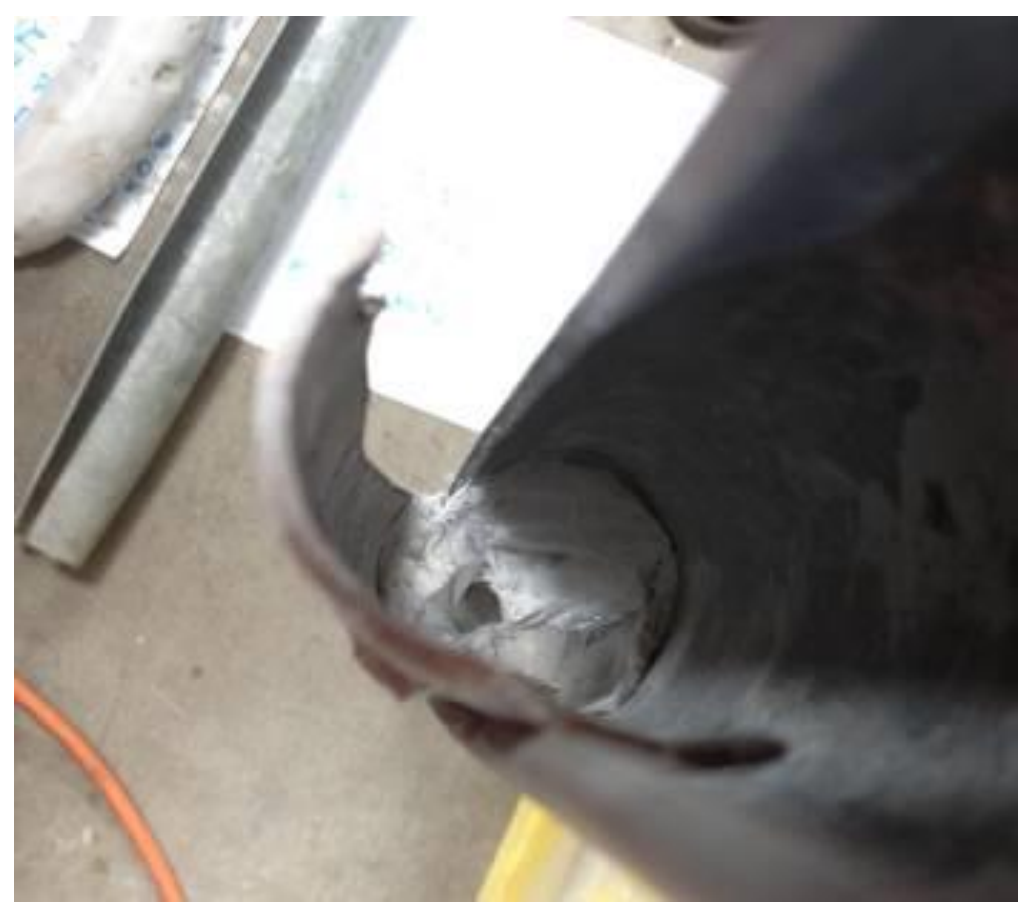

Figure 6 Final rupture of Stiff Split Set retaining flap

A sample of the expanded grout material was examined and found to be relatively soft but when it was contained within the Stiff Split Set it substantially increased the radial stiffness of the Stiff Split Set.

The results of the significant change in diameter of the Stiff Spilt Set provided encouragement to undertake preliminary field trials of the expanding grout with Stiff Split Sets. These were conducted at a mine site in South East Asia in very poor quality, argillic clay.

The mine's Ground Control Management Plan (GCMP) specified an anchorage strength requirement for Split Sets of $3.3 \mathrm{t} / \mathrm{m}$ embedment. This had been achieved previously in Fair to Poor ground by grouting Split Sets after they were installed. The mine operator reported confidence with this approach citing a typical friction of $4 \mathrm{t} / \mathrm{m}$ within the first few days after grouting. Manual grouting occurred sometime after bolt installation and on some occasions the firing of bored out cuts had to be delayed because the grout crew had not grouted bolts up to the face.

In this situation, the installation of one pass grouted Split Sets that could achieve the required frictional anchorage, would provide productivity improvements and potentially increased support capacity. The plan was to install expanding Stiff Split Sets into the different types of ground conditions at the mine with most interest being on the areas of poorest ground conditions where substandard frictional anchorage $(<<3.3 \mathrm{t} / \mathrm{m})$ was a common occurrence.

A $600 \mathrm{~mm}$ long swelling product sausage was saturated in water and placed approximately $600 \mathrm{~mm}$ from the toe of a number of $2.4 \mathrm{~m}$ long Stiff Split Set bolts. The rest of the bolt length, and the toe, were filled with standard saturated grout sausages used with conventional Stiff Split Set installations. The bolt was then installed into a hole drilled with a $41.9 \mathrm{~mm}$ diameter bit.

Grouted $2.4 \mathrm{~m}$ long Split Sets were required to achieve eight tonnes of pull-out resistance which equates to a friction of about $3.3 \mathrm{t} / \mathrm{m}$.

\section{$3 \quad$ Results}

Nine $46 \mathrm{~mm}$ diameter, $2.4 \mathrm{~m}$ long, expanding Stiff Spilt Set test bolts were installed in very poor argillic clay ground conditions. Due to damage of collar rings and damage to the testing ram, only six of these bolts could be successfully tested 18 days after installation. 
Pull test results were obtained as shown in Table 2:

Table 2 Pull test results in very poor argillic clay ${ }^{1}$

\begin{tabular}{cccc}
\hline Hole No. & $\begin{array}{c}\text { Pull Test Load At Bolt Slip } \\
(\mathbf{t})\end{array}$ & Notes & $\begin{array}{c}\mathbf{t} / \mathbf{m} \\
\text { (For Assumed Bond Length of 2.3 } \mathbf{~ m} \text { ) }\end{array}$ \\
\hline 1 & 17 & Stop test & 7.4 \\
2 & 17 & Stop test & 7.4 \\
3 & 15 & Stop test & 6.5 \\
4 & 15 & Stop test & 6.5 \\
5 & 15 & Stop test & 6.5 \\
6 & 14 & Ring failure & 6.1 \\
\hline
\end{tabular}

${ }^{1}$ Tests conducted and results supplied by Split Set Mining Systems

These results are extremely encouraging given that they showed a significant increase in the frictional resistance compared to the conventionally grouted Split Sets at the site. As described above, site tests on post grouted Split Sets in this ground gave typical results $<<3.3 \mathrm{t} / \mathrm{m}$, whereas these initial tests on expanding Stiff Split Sets achieved an average $6.7 \mathrm{t} / \mathrm{m}$. Further testing is underway at the time of writing of this paper.

The ability of the expanding grout to locally deform the Stiff Split Set is considered to be a major improvement to its application in soft, very poor ground. Depending on the distribution of expanding grout cartridges along the length of the Stiff Split Set, the deformation can occur along its entire length or at specific points where the Stiff Split Set can deform into weak zones along the hole.

These initial tests show that bolt swelling can significantly increase friction in very poor ground and if required the increased friction can be prescribed for various segments of the bolt, i.e. toe, collar, centre, etc. The ability to prescribe an increase in friction may create many opportunities to customise the ground support to suit the specific ground conditions and support requirements at a given mine site.

As an example, a $2.4 \mathrm{~m}$ Stiff Split Set bolt with a high toe friction could be engineered to provide enough frictional resistance to allow the bolt to slip at a load close to its tensile strength to allow it to absorb energy. Assuming the expanded part of the bolt developed $15 \mathrm{t} / \mathrm{m}$ in good ground, the following design is possible:

$$
\begin{gathered}
0.5 \mathrm{~m} \text { at } 15 \mathrm{t} / \mathrm{m}=7.5 \mathrm{t} \\
(2.3-0.5 \mathrm{~m}) \text { at } 5 \mathrm{t} / \mathrm{m}=9.0 \mathrm{t} \\
\text { Total pull-out load }=16.5 \mathrm{t}
\end{gathered}
$$

\section{$4 \quad$ Conclusions}

A common form of rockbolting in Australia, the Split Set, has gained industry wide acceptance because of the simple method for installation. The bolt performance is largely controlled by the friction developed between the bolt and the rock and in its conventional form; a substantial amount of a $2.4 \mathrm{~m}$ long bolt's tensile strength is wasted. Improvements in frictional resistance between the bolt and the rock have been gained by grouting Split Sets and with the expanding grout option discussed in this paper, the possibility of increasing friction further, especially in soft ground conditions is now a ground reinforcement option. This has the potential to be able to create a Spilt Set with variable anchor capabilities including a higher strength point anchor. The ability to increase the friction and to create zones of high friction along the specific parts of the bolt length may transform the Split Set's support capability. 


\section{Acknowledgements}

The authors acknowledge the assistance of Ben Roache from Mining One for reviewing and formatting this paper, Mining One Pty. Ltd for allowing this paper to be written, Gazmick Pty Ltd. for developing the concepts and patenting the Expanding Stiff Split Set and Split Set Mining Systems for assisting with trials, providing the pull test data and development of these products.

\section{References}

Davison, G.R. (2008) The development of industry-friendly rockbolts, in Proceedings First Southern Hemisphere International Rock Mechanics Symposium (SHIRMS 2008) Vol. 1 - Mining and Civil, Y. Potvin, J. Carter, A. Dyskin and R. Jeffery (eds), SHIRMS, 16-19 September 2008, Perth, Australia, Australian Centre for Geomechanics, Perth, pp. 579-587.

Fuller, P.G. and Dugan, K.J. (1992) Factors affecting ground support performance in mining, in Proceedings 5th Underground Operator's Conference, 14-16 July 1992, Ballarat, Australia, Australasian Institute of Mining and Metallurgy, pp. 139-144.

Thompson, A.G. and Finn, D.J. (1999) The performance of grouted split tube rockbolt systems, in Proceedings Rock Support and Reinforcement Practice in Mining, E. Villaescusa, C.R. Windsor and A.G. Thompson (eds), Balkema, Rotterdam, pp. 91-102.

Villaescusa, E. and Wright, J. (1997) Permanent excavation support using cement grouted Split Set bolts, in Proceedings International Symposium on Rock Support, Lillehammer, Norwegian Society of Chartered Engineers, Norway, pp. 660-670. 